\title{
Laser Doppler vibrometry experiment on a piezo-driven slot synthetic jet in water
}

\author{
Zuzana Broučková ${ }^{1, a}$, Tomáš Vit' ${ }^{2}$ and Zdeněk Trávníček ${ }^{1}$ \\ ${ }^{I}$ Institute of Thermomechanics AS CR, 18200 Prague, Czech Republic \\ ${ }^{2}$ Technical University of Liberec, Studentská 1402/2, Liberec, Czech Republic
}

\begin{abstract}
The present study deals with a slot synthetic jet (SJ) issuing from an actuator into quiescent surroundings and driven by a piezoceramic transducer. The actuator slot width was $0.36 \mathrm{~mm}$, with a drive frequency proposed near the theoretical natural frequency of the actuator. The working fluid was water at room temperature. The present experiments used flow visualization (a laser-induced fluorescence technique) and laser Doppler vibrometry methods. Flow visualization was used to identify SJ formation, to demonstrate its function, and to estimate SJ velocity. Laser Doppler vibrometry was used to quantify diaphragm displacement and refine operating parameters. Phase averaging yielded a spatial and temporal diaphragm deflection during the actuation period. Taking incompressibility and continuity into consideration, the velocity in the actuator slot and the Reynolds number of the SJ were evaluated as $0.21 \mathrm{~m} / \mathrm{s}$ and 157 , respectively. The present results confirmed a SJ actuator function at the resonance frequency of approximately $46 \mathrm{~Hz}$, which corresponds closely with the theoretical evaluation. The laser Doppler vibrometry results corresponded closely with an estimation of SJ velocity by the present flow visualization.
\end{abstract}

\section{Introduction}

A synthetic jet (SJ) is a fluid jet flow that is generated during an oscillatory process of fluid suction and extrusion between a cavity and its surroundings - Smith and Glezer [1]. The time-mean mass flux through the actuator orifice is zero, therefore a SJ is frequently known as a zero-net-mass-flux jet - Cater and Soria [2]. The SJ actuator can be considered as an oscillatory vorticity generator - Yehoshua and Seifert [3].

Most likely, the first relevant actuator was proposed by Dauphinee [4], who designed and used a laboratory air-jet generator - SJ actuators in today's terminology (note that the expression "synthetic jet" originated with James et al. [5]).

A desirable feature of SJ actuators are their relative simplicity as neither blower nor piping to supply fluid is required. Therefore, experimental, theoretical, and numerical investigations have developed distinctly - e.g. Kral et al. [6], Lee and Goldstein [7], Mallinson et al. [8], Glezer and Amitay [9], and Kordík and Trávníček [10]. Formation criteria (the necessary conditions for creating a SJ) and flowfield regimes of SJs were studied by Holman et al. [11], Zhou et al. [12], Xia and Zhong [13], Trávníček et al. [14], and McGuinn et al. [15].

SJs are a promising alternative for various applications of active flow control, such as jet vectoring and exciting (Pack and Seifert [16], Smith and Glezer

\footnotetext{
${ }^{\mathrm{a}}$ Corresponding author: brouckova@it.cas.cz
}

[17], Tamburello and Amitay [18], Ben Chiekh et al. [19]); for flow control/triggering of mean flow development (Hong [20], Watson and Sigurdson [21]); for flow control in external aerodynamics (Chen and Beeler [22], Mittal and Rampunggoon [23], Amitay and Glezer [24], Tensi et al. [25]); and for flow control in internal aerodynamics (Ben Chiekh et al. [26]).

Another application field focuses on convective heat transfer on walls. A pioneering conference paper by Yassour et al. [27] dealt with an annular impinging SJ. Nearly two decades later, SJs and impinging SJs for cooling applications have been investigated by several other authors [28-37], particularly on a micro scale, e.g. in microelectromechanical systems (MEMS) - Tesař [38]. A typical problem here is the cooling of highly loaded electronic components in microchannels - see Timchenko et al. [39], Lee et al. [40, 41], and Trávníček et al. [42].

A typical SJ actuator consists of a sealed cavity with an orifice or nozzle for fluid exchange with the surroundings. The cavity is equipped with oscillating walls in the shape of diaphragms or pistons, which transfer mechanical oscillations to the fluid. The mechanical oscillations can be generated by a separate motor, which is connected via a reciprocatingly acting mechanism with the actuator diaphragm/piston. An obvious advantage of the separate motor is the possibility to create an arbitrary actuation cycle with a precisely 
predefined diaphragm/piston displacement during the cycle, independent of geometry and working fluid properties. For example, Gilarranz et al. [43] designed a high-power SJ actuator with a driving mechanism consisting of a DC motor, crankshaft, and connecting rod driving the actuator piston. The working fluid was air.

Designs utilizing a separate motor driving a pistontype SJ actuator are frequently used when water is the working fluid. One of the reasons for this is the possibility to easily isolate the drive electronics from the surrounding water. For example, Cater and Soria [2] investigated a water $\mathrm{SJ}$ issuing from a piston-type SJ actuator that was sinusoidally driven by a mechanism consisting of a stepper motor, lead screw, and sliding block. Di Cicca and Iuso [44] used a SJ actuator with a sinusoidally oscillating piston driven by a cam mounted onto the shaft of a stepper motor. Hsu et al. [45] used another mechanism for driving a piston-type SJ actuator consisting of a DC motor and a Scotch yoke mechanism with a precise sinusoidal driving cycle. Wang et al. [46] focused on non-sinusoidal actuation cycles with shortened (thus more powerful) extrusion strokes. They used a piston-type SJ actuator driven by a programmable electromotor with a crank mechanism. Xia and Zhong [13] investigated liquid SJs in highly viscous liquids such as sugar solutions or silicone oil. They used a piston-type SJ actuator, sinusoidally driven by a mechanism consisting of the magnetic shaker connected via a steel rod to the piston.

Unlike SJ actuators driven via separate mechanisms, another approach uses the integration of suitable transducers into a SJ actuator design. A clear benefit is more compact arrangements. The suitable transducers can be based, e.g., on the electrodynamic, piezoelectric, electromagnetic, electrostatic, thermopneumatic, bimetallic, electrohydrodynamic, and shape memory alloy principles. Obviously, an evaluation of the diaphragm/piston displacement (thus the SJ velocity, and thus the SJ Reynolds number) is more complicated because it results from the dynamic behavior of the entire electro-mechanical system of the transducer-actuator. Moreover, the behavior is a frequency dependent attribute, and a complex system response depends on geometry and material properties.

The majority of experimental SJ studies uses transducers based on either electrodynamic or piezoelectric principles. Namely, the majority of experimental SJ actuators uses commercially available loudspeakers or piezoelements. A typical SJ actuator uses one, two, or more driven diaphragms. For example, Yang [47] used a dual-diaphragm piezoelectrically driven SJ actuator to generate a two-dimensional SJ issuing from a $0.5 \times 35 \mathrm{~mm}$ slot; Smith and Swift [48] used a set of eight loudspeakers to generate a two-dimensional SJ issuing from a $5.1 \times 241 \mathrm{~mm}$ slot; and Chen and Beeler [22] used a set of 14 pairs of piezoelements to generate a twodimensional SJ issuing from a $0.5 \times 762 \mathrm{~mm}$ slot. In the mentioned studies [47, 48, 22], air was the working fluid.

The most effective operating frequency follows one of the resonance frequencies of the system. Peaks in the frequency characteristics of the loudspeaker-driven SJ actuators are usually not as sharp as those for the piezoelectric-driven SJ actuators. Therefore, the use of loudspeakers allows a relatively wider range of driving frequencies - in comparison with the rather narrow frequency range typical for piezoelements.

Another common problem is evaluation of SJ parameters, which are typically problematic for very small velocities and sizes, i.e. for the small Reynolds numbers required by micro applications [38-41]. Obviously, the SJ frequency corresponds with the supply frequency, which is an input experimental parameter. On the other hand, an evaluation of the SJ velocity cycle can present a serious experimental challenge. Namely, the SJ velocity can be directly measured by means of advanced methods in local and global anemometry such as hot-wire anemometry, laser Doppler anemometry, and particle image velocimetry. These methods are very useful for laboratory conditions, but they can cause serious complications under conditions of particular (flow control or cooling) applications due to either the invasive character of probes or an obstructed installation of an optic path and flow feeding by tracking particles. Therefore, a predetermination of the SJ velocity is often desirable. Obviously, predetermination of the velocity can easily be made in the above-mentioned case of separate driving mechanisms. On the other hand, integrated transducer systems can be modeled theoretically by means of a lumped parameter approach most likely, the first studies incorporating the lumped element model (LEM) and loudspeaker-driven and piezoelectric-driven SJ actuators were presented by McCormick [49] and Gallas et al. [50], respectively. However, a usable application of LEM frequently needs additional measurements such as cavity pressure cycles Persoons and O'Donovan [51]. To overcome this disadvantage, another method of SJ velocity evaluation has recently been proposed by Kordík et al. [52]. This method is based on simple measurements of the actuator electrical inputs (alternating current and voltage). However, none of the models is a self-salvable key, and the method [52] is only valid for well-defined loudspeaker-based actuators using air as the working fluid.

Piezoelectric-driven SJ actuators can be submerged in water, as was presented by James et al. [5] and Trávníček et al. [42]. Although a design of a submerged piezoelectric-driven SJ actuator is very compact, a predetermination of the SJ velocities at very low sizes and Reynolds numbers is problematic. On the other hand, low Reynolds numbers conditions imply a possibility to evaluate the SJ velocity from the diaphragm deflection, while allowing for incompressibility and continuity conditions.

The aim of this study was to demonstrate a function of piezoelectric-driven SJ actuators submerged in water, and to evaluate the SJ velocity by means of laser Doppler vibrometry measurements of the deflection of the oscillating diaphragm. To the best of the authors' knowledge, no similar evaluation has been presented or is available in literature. Certainly, velocity measurements of a oscillating piezoceramic diaphragm using a laser vibrometer have been conducted - e.g. Gallas et al. [50], however, the diaphragm was removed from the SJ 
actuator and the working fluid was air or the measurement was performed in a vacuum to eliminate fluid loading effects.

\section{Experimental investigation}

\subsection{Problem parameters}

The two-dimensional SJ was characterized by two length scales, namely the output orifice width $B$, and the stroke length $L_{0}=U_{0} T$, where $U_{0}$ is the time-mean orifice velocity and $T$ is the time period ( $T=1 / f$, where $f$ is the actuating frequency). Assuming the slug flow model (i.e. a uniform velocity profile in the actuator output orifice), $U_{0}$ can be evaluated from the orifice centerline velocity:

$$
U_{0}=\frac{1}{T} \int_{0}^{T_{\mathrm{E}}} u_{0}(t) d t
$$

where $T_{\mathrm{E}}$ is the extrusion time (e.g., $T_{\mathrm{E}}=T / 2$ at a common sinusoidal waveform of $\left.u_{0}(t)\right)$, and $u_{0}$ is the velocity at the orifice exit. Thus, the stroke length is defined as $L_{0}=U_{0} T$.

To characterize the SJ, two dimensionless parameters were used, namely the dimensionless extrusion stroke length $L_{0} /(2 B)$ and the Reynolds number $R e=U_{0} 2 B / v$, where the characteristic length is the hydraulic diameter of the slot $(2 B)$ and $B$ is the slot width.

The Strouhal and Stokes numbers are dependent parameters, defined as a combination of $L_{0} /(2 B)$ with $R e$. Note that different authors use different definitions of the Strouhal and Stokes numbers, which can complicate a comparison with the references. Therefore, the present paper only uses the stated and sufficient pair of parameters: $L_{0} /(2 B)$ and $R e$.

\subsection{Experimental setup}

Figure 1 shows a schematic view of the present actuator. The actuator body was constructed from PMMA (polymethyl methacrylate). It was equipped with a piezoelectric diaphragm (1), comprising a KPS-100 piezoceramic transducer with a diaphragm diameter of $D_{\mathrm{D}}=39.5 \mathrm{~mm}$. The cavity (2) diameter and depth were $44 \mathrm{~mm}$ and $6 \mathrm{~mm}$, respectively. The SJ issued from a slot (3) on the top of the actuator. The slot width and length were $B=0.36 \mathrm{~mm}$ and $40 \mathrm{~mm}$, respectively. The SJ coordinate system $x, y, z$, and the $r_{\mathrm{a}-\mathrm{c}}$ and $r_{\mathrm{b}-\mathrm{d}}$ coordinates were useful for diaphragm measurement, as shown in Figure 1. The working fluid was water. The experiments were made in a glass tank of water with the following dimensions: height $\times$ length $\times$ depth $=150 \times 245 \times 140$ $\mathrm{mm}$.

The actuator was driven by the sinusoidal current from a sweep/function generator (Agilent 33210A), which was amplified by an amplifier (RH Sound ST2250BC). The true root-mean-square (RMS) of the alternating current, voltage, and power were measured with an accuracy of $\pm 0.5 \%, \pm 0.5 \%$, and $\pm 1 \%$, respectively, by a digital multimeter constructed in-house and with a $13 \mathrm{kHz}$ sampling frequency. The present study used low frequency actuations at the near resonance frequency of $f=46.4 \mathrm{~Hz}$, with an RMS voltage of $18.0 \mathrm{~V}$. For this supply, the electrical power was approximately $17 \mathrm{~mW}$. Note that the capacitive character of the piezoceramic transducer did not allow the electrical power to be evaluated as the product of the RMS values of the alternating current and voltage because the phase angle between them was not negligible in this case - it was evaluated from $23^{\circ}$ to $28^{\circ}$.
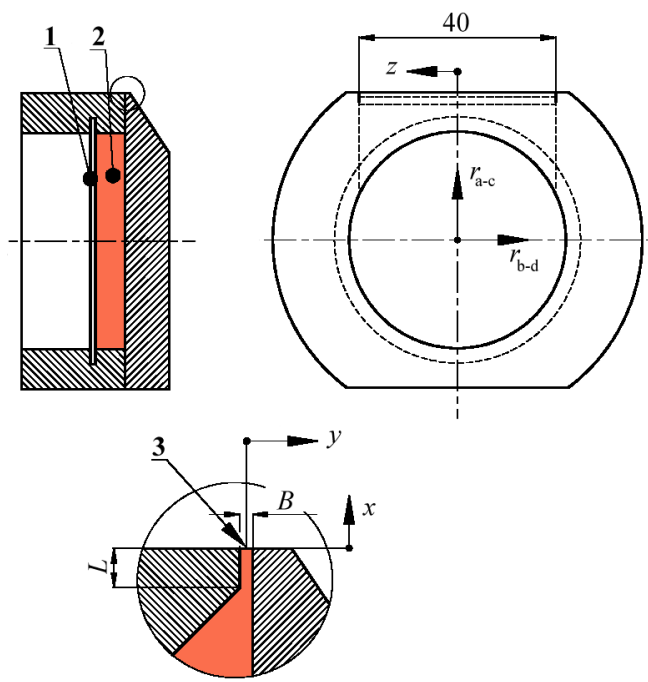

Figure 1. Investigated SJ actuator, 1: diaphragms, 2: cavity, 3: slot orifice.

The flow visualization used the laser induced fluorescence (LIF) technique. The LIF technique is based on the fluorescence of atoms or molecules. When a fluorescence dye is placed under a light at a suitable wavelength, the dye absorbs the energy and consequently reemits part of it at higher wavelengths (see e.g. Seuntiens et al. [53] for more details).

In this study, the Rhodamine B was chosen as the fluorescence dye (with an absorption wavelength of 460 to $590 \mathrm{~nm}$, and emission wavelength of 560 to $670 \mathrm{~nm}$ ) see [54]. Rhodamine B is usually used for temperature measurements because it has a temperature-dependent emission intensity. However, in the present study this effect was not used, the present experiments were approximately isothermal.

The temperature of the water was measured using a NTC thermistor sensor (Ahlborn AMR, Therm 2280-3). All experiments were made after thorough temperature equalization at room temperature. In this study, the temperature was $22^{\circ} \mathrm{C}$.

The switched off SJ actuator was placed into the glass tank filled with pure, demineralised water, which was prepared in four-stage reverse osmosis water purification system. The cavity of the actuator was filled carefully with the dye solution (a highly concentrated solution of Rhodamine B). Then, the actuator was turned on. The extruded fluid puffs were dye-stained. The flow was lit by a laser sheet (Nd:Yag Litron, NANO S 65-15 pulsed laser, with a wavelength of $532 \mathrm{~nm}$ and an output of $65 \mathrm{~mJ}$, with cylindrical optics). The laser sheet was perpendicular to the slot of the actuator, i.e. in the plane 
of $x-y$, see Figure 1. The frequency of the laser was 11.6 $\mathrm{Hz}$ (i.e. one-fourth of the working frequency of the actuator). Pictures of the visible, phase-locked flow field pattern (streaklines) were taken using a HiSense Neo digital camera (2560 x 2160 pixels, 16-bit). The camera was equipped with a Tokina $100 \mathrm{~mm}$ F2.8 Macro D lens. To remove the laser light from the pictures, the color filter (cut-off wavelength of $570 \mathrm{~nm}$ ) was used. The camera was used to trigger the laser pulse. The measurement system was controlled using DynamicStudio v3.40 Software (Dantec Dynamics).

Measurement of the oscillating piezoceramic diaphragm was made by the Laser Doppler Vibrometry (LDV). A portable digital vibrometer (Ometron VH$1000-\mathrm{D}, \mathrm{B} \& \mathrm{~K}$ 8338) was used to measure the velocity of the selected points of the diaphragm surface. The frequency range of the vibrometer was $0.5 \mathrm{~Hz}-22 \mathrm{kHz}$, and its velocity ranges (peak-peak) were $20 \mathrm{~mm} / \mathrm{s}$, $100 \mathrm{~mm} / \mathrm{s}$, and $500 \mathrm{~mm} / \mathrm{s}$. An NI PCI-data-acquisition device $6023 \mathrm{E}$ was used with a typical sampling frequency and number of samples of $10 \mathrm{kHz}$ and 16,384, respectively. The data-acquisition process utilized two channels, and recorded the LDV data and the reference TTL signal from the sweep/function generator. The procedure for data post processing, including phase averaging, was developed in MATLAB.

\section{Results and discussion}

As stated above, the chosen operating frequency should follow the resonance behavior of the system. Considering fluid incompressibility, the potential energy of the diaphragm is transformed into the kinetic energy of the fluid during each period. Assuming small displacements conditions, the potential energy of the diaphragm is considered as the energy of a linear spring. If the steady overpressure $p$ causes a steady displacement of the diaphragm center $\Delta x$, the diaphragm spring constant is defined as $K_{\mathrm{P}}=p / \Delta x$. The kinetic energy of $\mathrm{SJ}$ is assumed to be captured in the fluid column of the effective length $L_{e}$, where $L_{e}=L+16 B /(3 \pi)$, where $L$ is the orifice length $(L=1.0 \mathrm{~mm}$, see Figure 1) - cf. Kinsler et al. [55]. Following derivation described in [56], the first natural frequency of the present actuator generating $\mathrm{SJ}$ can be derived as

$$
f=\frac{1}{2 \pi c} \sqrt{\frac{A K_{\mathrm{P}}}{\rho A_{\mathrm{D}} L_{\mathrm{e}}}}
$$

where $c$ is the shape constant of the diaphragm deflection volume (from 0.5 for paraboloid to 1 for cylinder), $A$ is the cross-sectional area of the actuator orifice $(A=B \times 40$ $\mathrm{mm}), A_{\mathrm{D}}$ is the area of the diaphragm $\left(A_{\mathrm{D}}=\pi D_{\mathrm{D}}^{2} / 4\right)$, and $\rho$ is the fluid (water) density, while $K_{\mathrm{P}}$ was evaluated by an auxiliary experiment and used recently [42] for the present diaphragms as $K_{\mathrm{P}}=2.9 \times 10^{6} \mathrm{~N} / \mathrm{m}^{3}$. For the present geometry (Figure 1) and parameters $(\rho=997$ $\mathrm{kg} / \mathrm{m}^{3}, c=0.5$ ), Eq. (2) yields the frequency $f=46.4 \mathrm{~Hz}$.

The preliminary visualization experiments were made in the range of $30-60 \mathrm{~Hz}$. The frequency dependence of the SJ formation was observed and the resonance was confirmed at $46-47 \mathrm{~Hz}$. Hence, the operating frequency was set at $f=46.4 \mathrm{~Hz}$.

Figure 2 shows a typical visualization of the SJ in the middle of the actuator slot $(z=0)$. The presented area is $7 \times 14 \mathrm{~mm}$ in size. In repeated experiments, the distance between the two vortices nearest to the SJ actuator was evaluated as $3.7-4.6 \mathrm{~mm}$. Assuming that this distance is comparable with $L_{0}$, we can estimate $U_{0}=L_{0} f$, which yields $U_{0}=0.17-0.21 \mathrm{~m} / \mathrm{s}$ and the related $R e=130-160$.

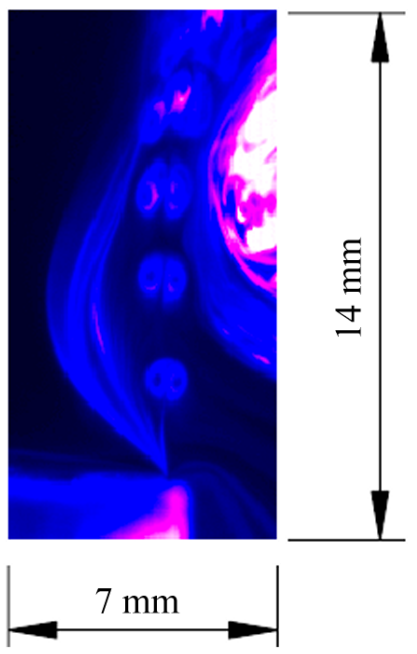

Figure 2. Visualization of SJ.

LDV velocity measurements of the oscillating diaphragm were made at 9 points on its surface, at diameters of 0,20 , and $34 \mathrm{~mm}$, as shown in Figure 3. The measurement was made from the diaphragm side with the piezoceramic transducer, while the other (brass) side forming the cavity. The diameters of the piezoceramic transducer and the cavity were $24 \mathrm{~mm}$ and $44 \mathrm{~mm}$, respectively, as shown in Figure 3. The LDV measurements were used to evaluate the SJ velocity $\left(U_{0}\right)$. Two evaluation methods are described in the following section. The former evaluation (paragraph 3.1.) is based on a simple point measurement of diaphragm center oscillations, while the later (par. 3.2.) is more relevant to the non-ideal spatial/temporal character of the diaphragm deflection.

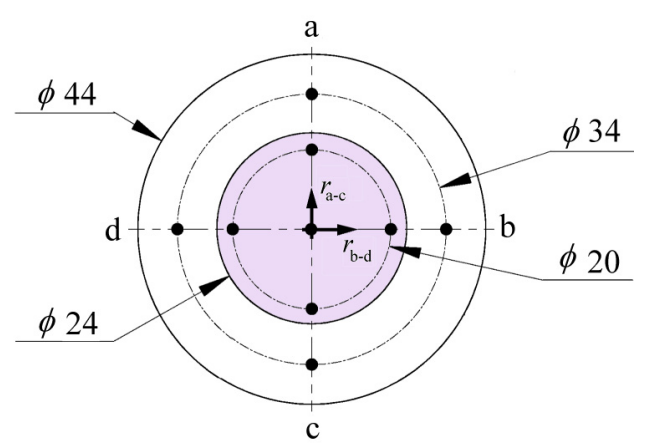

Figure 3. Arrangement of 9 points for LDV velocity measurements of the oscillating diaphragm. The diameters of $24 \mathrm{~mm}$ and $44 \mathrm{~mm}$ show sizes the piezoceramic transducer and the cavity, respectively. 


\subsection{Oscillation of the diaphragm center}

Assuming the instantaneous position of the diaphragm center in time as

$$
y(t)=-Y_{\max } \cos (\varphi),
$$

where $Y_{\max }$ is the diaphragm displacement amplitude from its middle position (yet unknown) and $\varphi=2 \pi f t$ is the phase angle (defined from the origin $\varphi=0$ as the beginning of the pump stroke), the diaphragm velocity can be derived as

$$
u(t)=d y / d t=2 \pi f Y_{\max } \sin (\varphi),
$$

where $2 \pi f Y_{\max }$ is the maximum diaphragm velocity.

Figure 4 shows the phase averaged velocity cycle at the diaphragm center, evaluated from the LDV experiment (LDV exp.). Note that the half cycles with the positive/negative velocities represents means the extrusion/suction strokes of SJ. The LDV experiment can be easily approximated by Eq. (4) with a maximum diaphragm velocity $2 \pi f Y_{\max }=12.5 \mathrm{~mm} / \mathrm{s}$. A very good agreement of both curves is evident from Figure 4 .

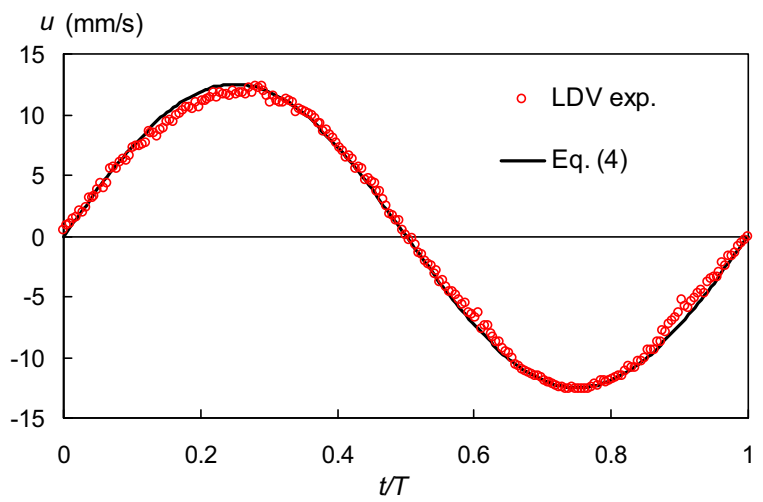

Figure 4. Velocity of the oscillating diaphragm center comparison of the LDV measurement (LDV exp.) and the sinusoidal approximation Eq. (4) with the maximum velocity of $12.5 \mathrm{~mm} / \mathrm{s}$.

Considering the slug flow (one-dimensional or "piston-like" flow) model for the fluid flow through the SJ slot nozzle, the harmonic motion of the diaphragm caused a harmonic motion of the fluid through the nozzle outlet:

$$
\mathrm{u}_{0}(t)=U_{\max } \sin (\varphi),
$$

where $U_{\max }$ is the maximum SJ velocity at the nozzle outlet. Based on the continuity equation of incompressible flow, this maximum flow velocity can easily be derived from the maximum diaphragm velocity as

$$
U_{\max }=2 c \pi f Y_{\max }\left(A_{\mathrm{D}} / A\right) .
$$

Assuming the paraboloidal shape of the diaphragm deflection $(c=0.5)$, the maximum $\mathrm{SJ}$ velocity is $U_{\max }=$
$0.53 \mathrm{~m} / \mathrm{s}$. Assuming the sinusoidal process $\left(U_{0}=U_{\max } /\right.$ $\pi$ ), we can evaluate $U_{0}=0.17 \mathrm{~m} / \mathrm{s}$ and $R e=127$.

\subsection{Deflection shape of the diaphragm}

Figures $5(\mathrm{a}, \mathrm{b})$ show the phase averaged velocity cycles evaluated from the LDV experiments at diameters of 20 $\mathrm{mm}$ and $34 \mathrm{~mm}$, respectively. The approximately sinusoidal character of the cycles and decreasing amplitude towards the diaphragm perimeter are obvious. On the other hand, the scattering of the cycles in Figure 5 $(a, b)$ demonstrate the non-symmetry of the deflected surface. The reasons are deviations from geometry, namely deviations in a diaphragm clamping around its perimeter, and the non-homogeneousness of the transducer piezoceramics. Moreover, some disturbances and discontinuities of the cycles (e.g. at the diaphragm perimeter, see curve $2 \mathrm{c}$ ) can be of an optical nature such as laser scattering at the rim of the piezoceramic transducer of the $24 \mathrm{~mm}$ diameter and a reflection of the non-uniformity of the measured surface. Minor reasons could be impurities in the water and non-uniformities of the glass wall.

It is worth noting the evident phase shift between the diaphragm center and perimeter. Figure 5 (b) shows an approximate phase delay of $t / T=0.096\left(\sim 35^{\circ}\right)$ at the perimeter compared with the center, as shown in Figure 4. The main reason for this was probably a fluid loading effect.

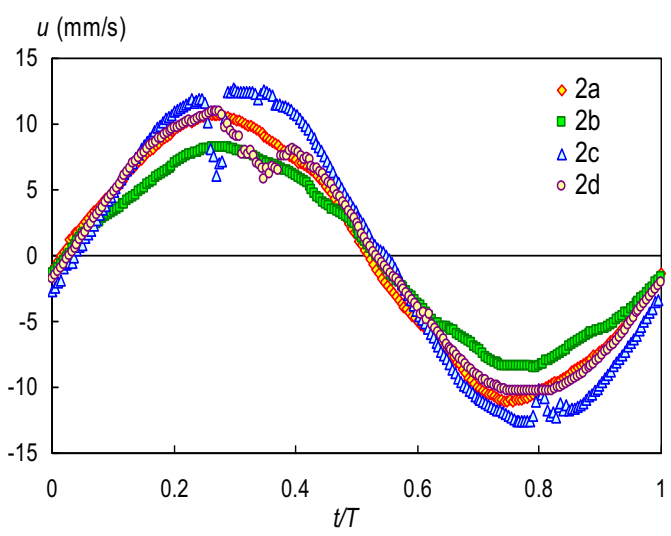

(a)

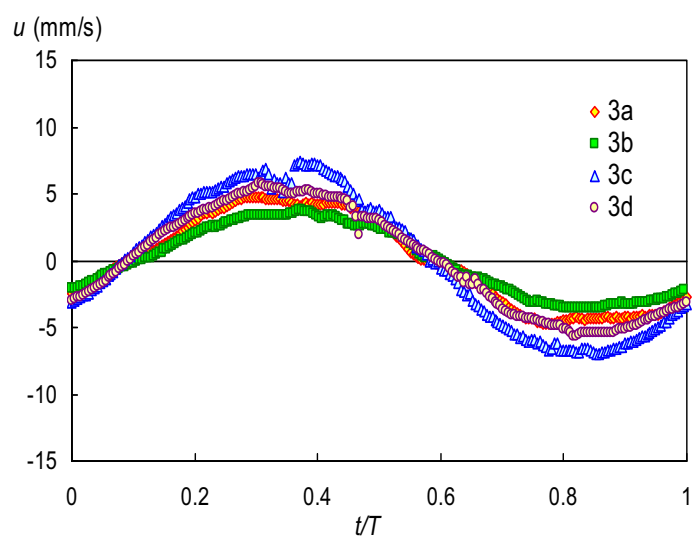

(b)

Figure 5. Velocity of the oscillating diaphragm at the diameters of (a) $20 \mathrm{~mm}$ and (b) $34 \mathrm{~mm}$. 
Following Eqs. (3 and 4), the local velocities from Figures 4 and 5 were integrated in time to obtain a local displacement $\Delta y$ in the measured diaphragm points. Typical profiles of the diaphragm displacement along the a-c line are shown in Figure 6 (a) in four instants during the cycle $t / T=0,0.25,0.5,0.75$.

Despite distinguishable deviations from ideal symmetry, Figure 6(a) corresponds with expectations. Sequentially, the local displacements measured at the same diameters were averaged and the resultant deflection profiles are presented as lines in Figures 6 (b and c) for the extrusion and suction strokes. To demonstrate deviations of point measurements from these averaged deflection lines, the data points are also presented in Figures 6 (b, c).

Finally, the averaged profiles of the diaphragm displacement have been integrated in the axi-symmetric coordinate system during the extrusion stroke to evaluate the fluid volume extruded during a cycle. Assuming incompressible flow and the slug flow model for the fluid flow through the SJ slot nozzle, the continuity equation yielded a SJ orifice velocity of $\underline{U}_{0}=0.21 \mathrm{~m} / \mathrm{s}$ and a Reynolds number of $\underline{R e}=157$. These values correspond reasonably well with the above-mentioned values of $U_{0}=$ $0.17 \mathrm{~m} / \mathrm{s}$ and $R e=127$, which were evaluated from a simple point LDV measurement of the diaphragm center oscillations.

\section{Conclusions}

A piezoelectric-driven synthetic jet actuator, submerged in a water tank, was designed and used to generate a plane synthetic jet. A slot nozzle of $0.36 \mathrm{~mm}$ in width and $40 \mathrm{~mm}$ in length was used. The driving frequency was proposed near the theoretical natural frequency of the actuator, $46.4 \mathrm{~Hz}$.

The experiments used flow visualization (laser induced fluorescence technique) and laser Doppler vibrometry methods. The visualization was synchronized at one-fourth of the working frequency of the actuator.

Diaphragm deflection was measured via displacements at 9 points on the surface. Phase averaging yielded a spatial and temporal diaphragm deflection during the actuation period. Considering incompressibility and the slug flow model for the fluid flow through the SJ slot orifice, the continuity equation yielded an orifice velocity of $U_{0}=0.21 \mathrm{~m} / \mathrm{s}$ and a Reynolds number of $R e=157$. These values correspond reasonably well with the results of a more simple point LDV measurement of the diaphragm center oscillations ( $U_{0}=0.17 \mathrm{~m} / \mathrm{s}$ and $R e=127$ ) as well as with estimations based on flow visualization $\left(U_{0}=0.17-0.21 \mathrm{~m} / \mathrm{s}\right.$ and $R e=$ 130-160).

\section{Acknowledgments}

We gratefully acknowledge the support of the Grant Agency of the Czech Republic - Czech Science Foundation (project no. 14-08888S) and the institutional support RVO:61388998. (a)

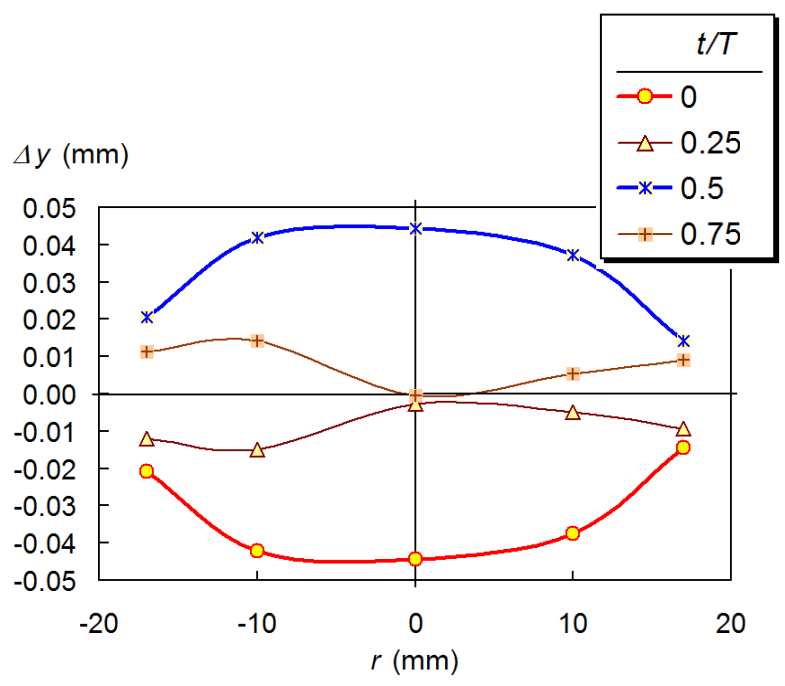

(b)

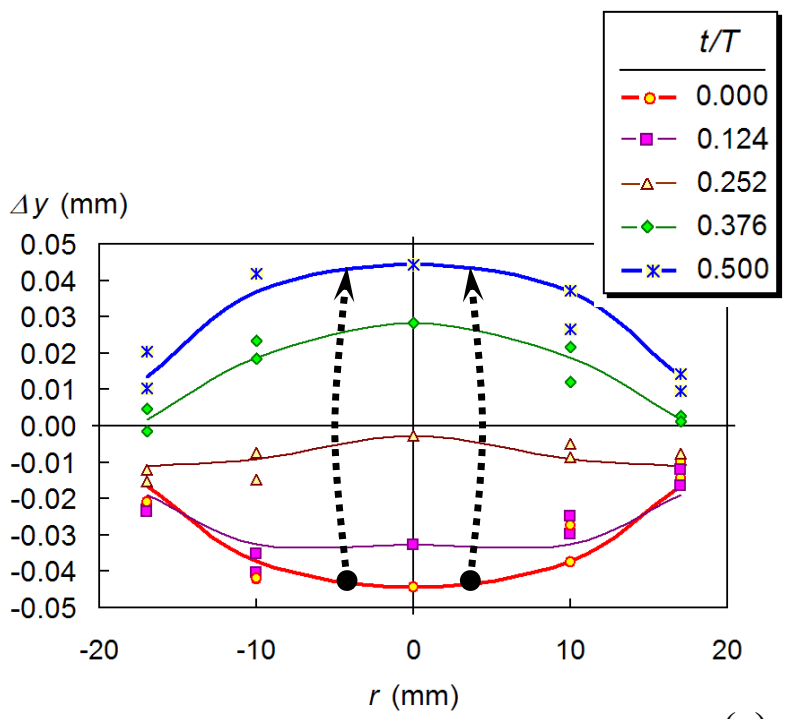

(c)

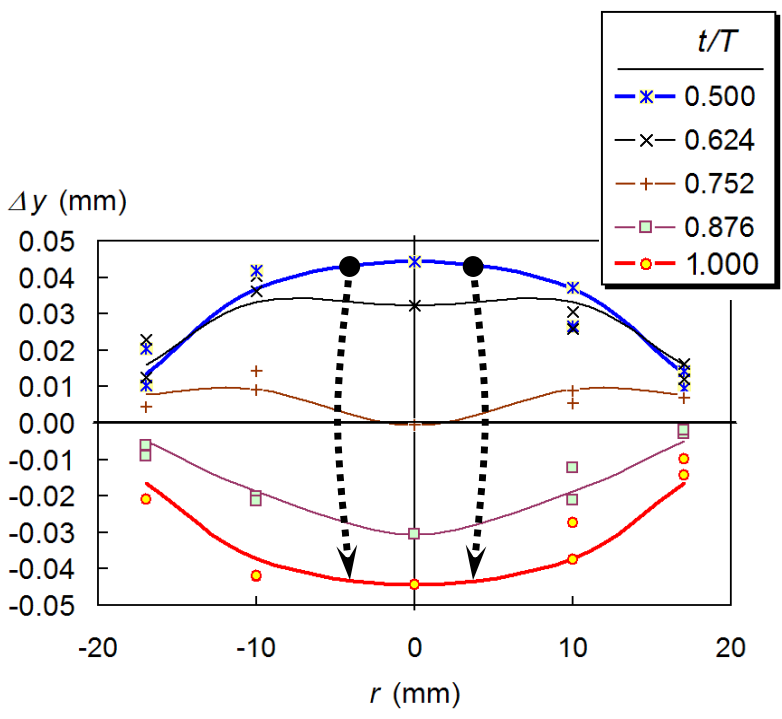

Figure 6. Profiles of the diaphragm displacement (a) measurement along the a-c line from Fig. 3, (b) extrusion stroke, profiles averaged from all four a,b,c,d measurements, (c) suction stroke, profiles averaged from all four a,b,c,d measurements. 


\section{References}

1. B.L. Smith, A. Glezer, Phys. Fluids, 10 (1998)

2. J.E. Cater, J. Soria, Jour. Fluid Mech. 472 (2002)

3. T. Yehoshua, A. Seifert, Aeronaut. J. 110 (2006)

4. T.M. Dauphinee, Rev. Sci. Instrum. 28 (1957)

5. R.D. James, J.W. Jacobs, A. Glezer, Phys Fluids 8 (1996)

6. L.D. Kral, J.F. Donovan, A.B. Cain, A.W. Cary, AIAA Paper 97-1824 (1997)

7. C.Y. Lee, D.B. Goldstein, AIAA Paper 2000-0406 (2000)

8. S.G. Mallinson, J.A. Reizes, G. Hong, Aeronaut. J. 105 (2001)

9. A. Glezer, M. Amitay, Annu. Rev. Fluid Mech. 34 (2002)

10. J. Kordík, Z. Trávníček, AIAA J. 51 (2013)

11. R. Holman, Y. Utturkar, R. Mittal, B.L. Smith, L. Cattafesta, AIAA J. 43 (2005)

12. J. Zhou, H. Tang, S. Zhong, AIAA J. 47 (2009)

13. Q. Xia, S. Zhong, Proc. Inst. Mech. Eng. Part C-J. Eng. Mech. Eng. Sci. 226 (2012)

14. Z. Trávníček, Z. Broučková, J. Kordík, AIAA J. 50 (2012)

15. A. McGuinn, R. Farrelly, T. Persoons, D.B. Murray, Exp. Therm. Fluid. Sci. 47 (2013)

16. L.G. Pack, A. Seifert, J. Aircraft 38 (2001)

17. B.L. Smith, A. Glezer, J. Fluid Mech. 458 (2002)

18. D.A. Tamburello, M. Amitay, J. Turbul. 8 (2007)

19. M. Ben Chiekh, M. Ferchichi, J.-C. Bera, Int. J. Heat Fluid Flow 32 (2011)

20. G. Hong, Sens. Actuator A-Phys. 132 (2006)

21. G.M.G. Watson, L.W. Sigurdson, Phys. Fluids 20 (2008)

22. F.-J. Chen, G.B. Beeler, AIAA Paper 2002-3273 (2002)

23. R. Mittal, P. Rampunggoon, Phys. Fluids 14 (2002)

24. M. Amitay, A. Glezer, Int. J. Heat Fluid Flow 23 (2002)

25. J. Tensi, I. Boué, F. Paillé, G. Dury, J. Visual. 5 (2002)

26. M. Ben Chiekh, J.C. Bera, M. Sunyach, J. Turbul. 4 (2003)

27. Y. Yassour, J. Stricker, M. Wolfshtein, Proceedings of the 8th International Heat Transfer Conference, Vol. 3, Hemisphere Publ., San Francisco, USA (1986)

28. Z. Trávníček, V. Tesař, Int. J. Heat Mass Transfer 46 (2003)

29. D.S. Kercher, J.-B. Lee, O. Brand, M.G. Allen, A. Glezer, IEEE Trans. Compon. Pack. Manuf. Technol. 26 (2003)

30. R. Mahalingam, N. Rumigny, A. Glezer, IEEE Transaction on Components and Packaging Technologies 27 (2004)

31. M.B. Gillespie, W.Z. Black, C. Rinehart, A. Glezer, Trans. ASME J. Heat Transfer 128 (2006)

32. M. Arik, Appl. Therm. Eng. 27 (2007)

33. P. Valiorgue, T. Persoons, A. McGuinn, D.B. Murray, Exp. Therm. Fluid Sci. 33 (2009)

34. M. Chaudhari, B. Puranik, A. Agrawal, Int. J. Heat Mass Transfer 53 (2010)
35. T. Persoons, A. McGuinn, D.B. Murray, Int. J. Heat Mass Transfer 54 (2011)

36. Z. Trávníček, L. Němcová, J. Kordík, V. Tesař, V. Kopecký, Int. J. Heat Mass Transfer 55 (2012)

37. Z. Trávníček, V.Tesař, Z. Broučková, K. Peszyński, Heat Transf. Eng. 35 (2014)

38. V. Tesař, Pressure-Driven Microfluidics. Artech House Boston, Massachusetts, USA (2007)

39. V. Timchenko, J.A.Reizes, E. Leonardi, Int. J. Numer. Methods Heat Fluid Flow 17 (2007)

40. A. Lee, G.H. Yeoh, V. Timchenko, J.A.Reizes, Sens. Actuator A-Phys. 184 (2012)

41. A. Lee, V. Timchenko, G.H. Yeoh, J.A.Reizes, Int. J. Heat Mass Transfer 55 (2012); Erratum in Int. J. Heat Mass Transfer 55 (2012)

42. Z. Trávníček, P. Dančová, J. Kordík, T. Vít, M. Pavelka, Trans. ASME J. Thermal Sci. Eng. Appl. 2 (2012)

43. J. L. Gilarranz, L. W. Traub, O. K. Rediniotis, ASME Trans. J. Fluids Eng. 127 (2005)

44. G.M. Di Cicca, G. Iuso, Fluid Dyn. Res. 39 (2007)

45. S.-S. Hsu, Z. Trávníček, C.-C. Chou, C.-C. Chen, A.B. Wang, Sens. Actuator A-Phys. 203 (2013)

46. J.-J. Wang, R.-Q. Shan, C. Zhang, L. Feng, Eur. J. Mech. B-Fluids 29 (2010)

47. A.-S. Yang, Smart Mater. Struct. 18 (2009)

48. B.L. Smith, G.W. Swift, Exp. Fluids 34 (2003)

49. D.C. McCormick, AIAA Paper 2000-0519 (2000)

50. Q. Gallas, R. Holman, T. Nishida, B. Carroll, M. Sheplak, L. Cattafesta, AIAA J. 41 (2003)

51. T. Persoons, T.S. O'Donovan, Phys. Fluids 19 (2007)

52. J. Kordík, Z. Broučková, T. Vít, M. Pavelka, Z. Trávníček, Exp. Fluids 55 (2014)

53. H.J. Seuntiëns, R. N. Kieft, C.C.M. Rindt, A.A. van Steenhoven, Exp. Fluids 31 (2001)

54. Planar-LIF software, Installation \& user's guide, Dantec Dynamics (2002)

55. L.E. Kinsler, A.R. Frey, A.B. Coppens, J.V. Sanders, Fundamentals of Acoustic. Wiley, New York (2000).

56. Z. Trávníček, A.I. Fedorchenko, A.-B. Wang, Sens. Actuator A-Phys. 120 (2005) 